\title{
ANALYZE SCIENTIFIC PRODUCTION AT THE FACULTY OF MEDICAL SCIENCES OF THE UNIVERSITY OF GUAYAQUIL
}

\author{
Dr. Jorge Daher Nader ${ }^{*}{ }^{凶}$, Dr. Amelia Patricia Panunzio ${ }^{1}$, Dr. Marlene Hernández \\ Navarro ${ }^{2}$ \\ ${ }^{* 1}$ Professor at the University of Guayaquil, Ecuador \\ 2 University of Zulia, Venezuela
}

DOI: https://doi.org/10.29121/granthaalayah.v8.i9.2020.1674

Article Type: Research Article

Article Citation: Dr. Jorge Daher Nader, Dr. Amelia Patricia Panunzio, and Dr. Marlene Hernández Navarro. (2020). ANALYZE SCIENTIFIC PRODUCTION AT THE FACULTY OF MEDICAL SCIENCES OF THE UNIVERSITY OF GUAYAQUIL. International Journal of Research -GRANTHAALAYAH, 8(9), 388-394.

https://doi.org/10.29121/granthaa layah.v8.i9.2020.1674

Received Date: 15 September 2020

Accepted Date: 30 September 2020

Keywords:

Analyze

Productivity

Scientific

Dimension

\section{ABSTRACT}

The results obtained in the analysis of the two sub-dimensions of the dimension are exposed: scientific production In general, the scientific production dimension addressed in the sub-dimensions scientific productivity and scientific results obtained a mean and SD of $2.38 \pm 1,171$ and $2.75 \pm 1,386$ respectively, classified as a medium level according to the opinion of the teachers, according to the scale used for such purposes.

\section{INTRODUCTION}

Table 1: Mean and standard deviation for the indicators of the SCIENTIFIC PRODUCTION DIMENSION. Questionnaire for teachers

\begin{tabular}{|c|c|}
\hline Subdimensions & Mean \pm DS \\
\hline Scientific Productivity & $2.38 \pm 1,171$ \\
Scientific Results & $2.75 \pm 1,386$ \\
\hline
\end{tabular}

Own Elaboration (Daher J, 2019) $n=197$ teachers

In general, the scientific production dimension addressed in the sub-dimensions scientific productivity and scientific results obtained a mean and SD of $2.38 \pm 1,171$ and $2.75 \pm 1,386$ respectively, classified as a medium level according to the opinion of the teachers, according to the scale used for such purposes. . It is necessary to point out

(C) 2020 The Author(s). This is an open access article distributed under the terms of the Creative Commons Attribution License, which permits unrestricted use, distribution, and reproduction in any medium, provided the original author and source are credited. 
that the time of dedication of the teachers and their training could have influenced the level obtained in this dimension.

As analyzed for the external funds management indicator, when considering the average level that results in the scientific productivity sub-dimension, the findings could coincide with what Moran and Taypes point out in a study that aimed to describe scientific production in medical education in Latin America in journals indexed in Scopus in the period 2011-2015, in which it was obtained as a result that of the 850 original articles evaluated 418 (49.2\%) had an author from Brazil, $129(15.2 \%)$ ) from Mexico, 82 (9.6\%) from Chile, 60 (7.1\%) from Colombia and 59 (6.9\%) from Cuba. Of the 21 Latin American countries evaluated, only 2 had more than 100 articles, this affirms the need to implement strategies and methodologies that enhance scientific production in universities.

This low production in Latin America with respect to other areas may be due to the lack of funding, incentives and research training programs in this area (Morán and Taype, 2017) (González, García and Dorta, 2016).

Publications are the key component of all scientific activity (Peralta, M Solis, Peralta, 2010), with research being one of the fundamental pillars of higher education today, along with teaching and outreach. Thus, scientific production becomes a key element within the quality of Higher Education (Álvarez and Juncosa, 2014).

In the last decade, the Ecuadorian government has promoted the increase in scientific production through the enactment of improvements in universities, incentives to obtain postgraduate degrees, the creation of scientific and technological transfer programs, and the provision of funds to finance inter-institutional projects. scientific research at the national and international level (Medina and others, 2016). These efforts have "awakened" Ecuador to scientific research and technological development, which is reflected in the increase in scientific results.

But there are still great challenges to be solved, Castillo JA, Michael A. P, 2019 states that the excessive work of the university professor in relation to administrative tasks in addition to research, sometimes the little understanding on the part of authorities who do not understand the concept of "Research" from the point of view of the commitment to research activities and resources, the complicated and over-controlled public procurement system that hinders the acquisition of laboratory equipment, supplies and reagents, the uncertainty in budget commitments, and the difficulty of the Bioethics committees to obtain informed consent. Such challenges can be decisive in university scientific production.

Table 2: T Student for the indicators of the SCIENTIFIC PRODUCTION DIMENSION. T-test for means of two paired samples

\begin{tabular}{|c|c|c|}
\hline & Variable 1 & Variable 2 \\
\hline Average & 2,385 & 2,75333333 \\
\hline Variance & 0,51599 & 0,21862667 \\
\hline Observations & 6 & 6 \\
\hline Pearson's correlation coefficient & $-0,6176185$ & \\
\hline Hypothetical difference of means & 0 & \\
\hline Degrees of freedom & 5 & \\
\hline T-statistic & $-0,8415168$ & \\
\hline $\mathrm{P}(\mathrm{T}<=\mathrm{t})$ one tail & 0,21922055 & \\
\hline Critical value of t (one tailed) & 2,01504837 & \\
\hline $\mathrm{P}(\mathrm{T}<=\mathrm{t})$ two tails & 0,43844111 & \\
\hline Critical value of $\mathrm{t}$ (two-tailed & 2,57058184 & \\
\hline
\end{tabular}

As can be seen in Table 2, when applying Student's t, a p value greater than 0.001 was obtained, so it can be stated that there are no significant differences between the means of the sub-dimensions corresponding to the scientific production dimension. 
Analyze Scientific Production at The Faculty of Medical Sciences of The University of Guayaquil

Table 3: Mean and standard deviation for the indicators of the SCIENTIFIC PRODUCTIVITY subdimension. Questionnaire for teachers

\begin{tabular}{|c|c|}
\hline Indicators & Mean \pm SD \\
\hline Articles published in magazines & $2,95 \pm 1,279$ \\
Articles published in SCOPUS journals & $2,49 \pm 1,268$ \\
Published books or chapters & $1,73 \pm 1,038$ \\
Number of patents & $1,32 \pm, 842$ \\
Articles with international cooperation & $2,65 \pm 1,041$ \\
Publication of articles as first author & $3,17 \pm 1,558$ \\
\hline
\end{tabular}

Table 3: ANOVA for the indicators of the scientific productivity subdimension

\begin{tabular}{|c|c|c|c|c|c|c|}
\hline \multicolumn{7}{|c|}{ ANOVA } \\
\hline & & \multicolumn{2}{|c|}{ Sum of squares gl } & Mean quadratic & $\mathrm{F}$ & Sig. \\
\hline \multirow[t]{3}{*}{ Publication in regional magazines } & Between groups & s 158,070 & 4 & 39,518 & \multicolumn{2}{|c|}{$46,686,000$} \\
\hline & Within groups & 162,519 & 193 &, 846 & & \\
\hline & Total & 320,589 & 197 & & & \\
\hline \multicolumn{2}{|c|}{ Publication in high impact journals Between groups } & 137,008 & 4 & 34,252 & 36,898 & 000 \\
\hline \multicolumn{2}{|c|}{\begin{tabular}{|l|} 
Within groups \\
\end{tabular}} & 178,230 & 193 & ,928 & & \\
\hline & Total & 315,239 & 197 & & & \\
\hline \multirow[t]{3}{*}{ Publication of books or chapters } & Between groups & 46,037 & 4 & 11,509 & 13,380 , & 000 \\
\hline & Within groups & 165,161 & 193 &, 860 & & \\
\hline & Total & 211,198 & 197 & & & \\
\hline \multirow[t]{3}{*}{ Obtaining patents } & Between groups & 12,031 & 4 & 3,008 & 4,554 & 002 \\
\hline & Within groups & 126,821 & 193 & ,661 & & \\
\hline & Total & 138,853 & 197 & & & \\
\hline \multirow[t]{3}{*}{ International cooperation articles } & Between groups & 53,687 & 4 & 13,422 & 16,224 & 000 \\
\hline & \begin{tabular}{|l|} 
Within groups \\
\end{tabular} & 158,841 & 193 &, 827 & & \\
\hline & Total & 212,528 & 197 & & & \\
\hline
\end{tabular}

As can be seen in table 3, there are significant differences between all the indicators analyzed except in obtaining patents in which the value obtained was greater than 0.001 . Below are the results obtained by the Tukey test.

Table 4: Tukey for the indicators of scientific productivity with statistically significant values

\begin{tabular}{|c|c|c|c|}
\hline Publication in reg & gional ma & azine & \\
\hline HSD Tu & ukeya,b & & \\
\hline Articles as first author $\mathrm{N}$ & $\mathrm{N}$ Subset & $\mathrm{r}$ alph & $=0.05$ \\
\hline & 1 & 2 & 3 \\
\hline 56 & 1,63 & & \\
\hline 2 & 3 & 2,67 & \\
\hline 42 & 42 & 2,98 & 2,98 \\
\hline 43 & 43 & 3,60 & 3,60 \\
\hline 53 & 53 & & 3,83 \\
\hline Sig. & 1,000 & ,096 & , 158 \\
\hline
\end{tabular}

\begin{tabular}{|c|c|c|c|}
\hline \multicolumn{4}{|c|}{ Publication in high impact magazines } \\
\hline \multicolumn{4}{|c|}{ HSD Tukey } \\
\hline Articles as first author & $\mathrm{N}$ & Subset for alpha $=0.05$ \\
\cline { 3 - 4 } & & 1 & 2 \\
\hline 1 & 56 & 1,23 & \\
\hline 2 & 3 & & 2,33 \\
\hline
\end{tabular}


Dr. Jorge Daher Nader, Dr. Amelia Patricia Panunzio, and Dr. Marlene Hernández Navarro

\begin{tabular}{|c|c|c|c|}
\hline 3 & 43 & & 2,58 \\
\hline 4 & 42 & & 3,17 \\
\hline 5 & 53 & & 3,23 \\
\hline Sig. & & 1,000 &, 159 \\
\hline
\end{tabular}

\begin{tabular}{|c|c|c|c|c|}
\hline \multicolumn{5}{|c|}{ Publication of books or book chapters } \\
\hline \multicolumn{5}{|c|}{ HSD Tukeya,b } \\
\hline Articles as first author & N & \multicolumn{3}{|c|}{ Subset for alpha $=0.05$} \\
\cline { 3 - 5 } & & 1 & 2 & 3 \\
\hline 2 & 3 & 1,00 & & \\
\hline 1 & 56 & 1,20 & 1,20 & \\
\hline 5 & 53 & 1,49 & 1,49 & 1,49 \\
\hline 3 & 43 & & 2,07 & 2,07 \\
\hline 4 & 42 & & & 2,43 \\
\hline Sig. & &, 695 &, 148 &, 100 \\
\hline
\end{tabular}

\begin{tabular}{|c|c|c|c|}
\hline \multicolumn{4}{|c|}{ International cooperation articles } \\
\hline \multicolumn{4}{|c|}{ HSD Tukeya,b } \\
\hline Articles as first author & $N$ & \multicolumn{2}{|c|}{} \\
\cline { 3 - 4 } & & 1 & 2 \\
\hline 2 & 3 & 1,00 & \\
\hline 1 & 56 & 1,13 & \\
\hline 5 & 53 & 1,30 & 1,30 \\
\hline 4 & 42 & & 2,19 \\
\hline 3 & 43 & & 2,30 \\
\hline Sig. & &, 927 &, 059 \\
\hline
\end{tabular}

Table 5: Mean and standard deviation for the indicators of the SCIENTIFIC RESULTS subdimension. Questionnaire for teachers

\begin{tabular}{|c|c|}
\hline Indicators & Mean \pm SD \\
\hline Citation by other researchers & $2,50 \pm 1,202$ \\
Co-authorship with students & $2,39 \pm 1,592$ \\
Disclosure at congresses & $2,91 \pm 1,358$ \\
Research tutoring & $3,50 \pm 1,395$ \\
Basic level research consultancy & $2,24 \pm 1,333$ \\
Execution of research projects & $2,98 \pm 1,441$ \\
\hline
\end{tabular}

Own Elaboration (Daher J, 2019) $n=197$ teachers

Regarding the opinion of the teachers regarding the indicators of the scientific results sub-dimension, table 12 shows the mean and SD scores obtained.

When inquiring about the citations of their articles by other researchers and the articles published together with the students, the score obtained was $2.50 \pm 1.202$ and $2.39 \pm 1.592$ respectively, which is at a medium level. In scientific research at the Faculty of Medical Sciences there has been a separation between teachers and students, the former may not give the value and importance of the latter as enhancers of research. Bascó, 2015, in his research, states that the success of student research lies in a good preparation or training of teachers and in adequate motivation, promotion and accompaniment of students with effective tutoring processes, in the space conceived for the Carrying out this activity, which has features that favor a guiding teaching practice, which guides the preparation of students from the performance of strategic tasks, for the appropriation of the knowledge, skills, habits and values that must characterize their research performance. These results are similar to those obtained by González Saldsaña J, 2017 who refers in his research that the largest number of articles belong to graduates as the first author, followed 
by teachers. No participation of undergraduate students is observed in this section, the activity of students being limited to joint participation with teachers or graduates.

Regarding the dissemination of research results in national and / or international congresses, the mean and SD obtained was $2.91 \pm 1.358$, medium level, this is an element to consider and improve in the faculty, the frequency of events has decreased considerably in the last year (2019), as authorities change, they are no longer planned as often as a year ago. Scientific dissemination requires the development of new strategies or the adaptation of models implemented in countries of the region. It is important to implement new spaces and technologies that bring science closer to the community, such as new thematic museums or open laboratories; and the improvement of capacities in researchers and scientists for the adequate dissemination and effective communication of their research results. (Franco R, 2018).

Regarding tutorials for undergraduate, master's and / or doctoral research and other basic level research, the mean and SD were $3.50 \pm 1.395$, and $2.98 \pm 1.441$ respectively, the appointed teachers have assigned work of degree for their advice or tutoring, this is an opportunity for teachers to enhance their knowledge in scientific research. On the other hand, advising on student research projects is not a satisfactory aspect in the Faculty of Medical Sciences. The mean and SD obtained was $2.24 \pm 1,333$, which corresponds to a medium level. There are very few teachers who are motivated to incorporate their students into integrative projects of knowledge or research hotbeds. The teacher plays a very important role in the productivity and development of the research hotbeds, he must be able to build academic knowledge through research. Formative research coupled with research hotbeds promotes autonomous, creative learning, l. (Villalba Cuéllar JC and González Serrano A, 2018) Projects are a way to develop competencies in students as well as investigative skills such as: planning, organizing and carrying out a common task in real environments. Thus, they are organized into work teams, assume individual and group responsibilities, carry out inquiries or investigations, solve. (Arias Sandoval L, 2017).

The teaching staff must be a facilitator in the development of capacities, skills and abilities of the student body, promoting collaborative and experiential work; In this sense, the role of projects can be of vital importance in pedagogical mediation activities, inside and outside the classroom, since it is learned through socialization, teamwork and, above all, problem solving through research. (Arias Sandoval L, 2017)

Table 6: ANOVA of the indicators of the scientific results subdimension

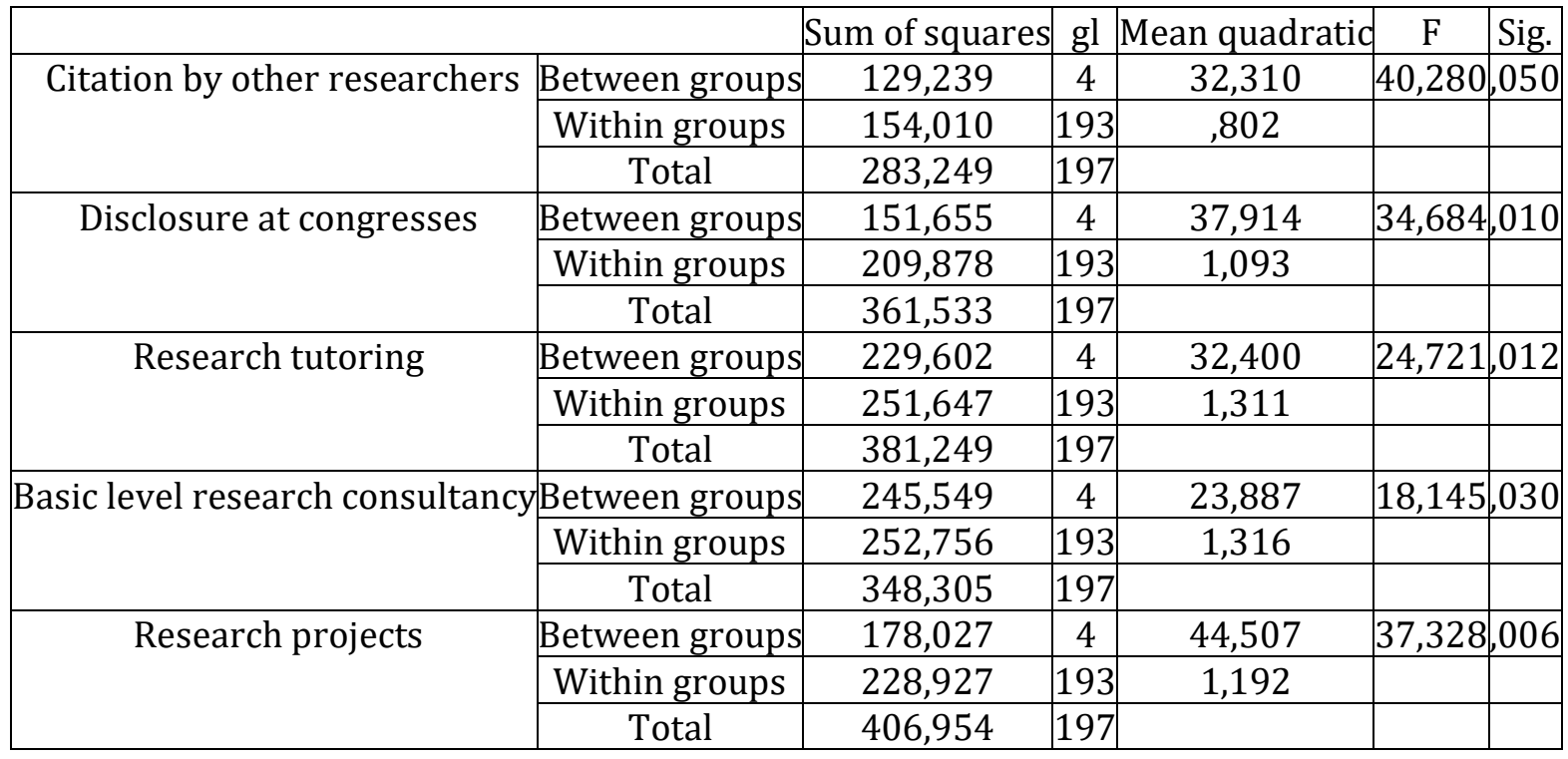

Table 6- shows the result of the Anova test carried out on the indicators of the scientific results subdimension, observing that there are no significant differences between them, since the p-value obtained in all cases was greater than 0.001 .

When analyzing the opinion of teachers in relation to scientific production, valuable information was obtained related to the need to increase the number of publications in high-impact journals as well as in regional ones, increase the number of articles with international cooperation, and the number of patents, increase the number of publications with students, increase the dissemination of scientific results in national and international conferences. 
The behavior presented could be influenced by the training of the teaching staff, since the number of teachers with a $\mathrm{PhD}$ degree is insufficient, although an increase in the number of teachers currently studying doctorates has been noted, this could improve scientific production in the faculty. The time of dedication could also be influencing these results, most of the teachers are part-time so they dedicate few hours to scientific research.

In summary, the analysis of this objective 2 offers an important contribution to the elaboration of the model for the strengthening of scientific production given by the need to increase the participation of teachers in research projects, in research groups, in scientific societies. On the other hand, the implementation of training is an imminent need to increase knowledge in research methodology and scientific writing.

\section{SOURCES OF FUNDING}

This research received no specific grant from any funding agency in the public, commercial, or not-for-profit sectors.

\section{CONFLICT OF INTEREST}

The author have declared that no competing interests exist.

\section{ACKNOWLEDGMENT}

None.

\section{REFERENCES}

[1] Evaluation of the academic satisfaction of the students of the Autonomous University of Nayarit. Revista Fuente, 2 (6), 46-56 López, (2014). Quality management models. European Model of Excellence. Spain: Colegio Sagrado Corazón Jesuitas León. Available at: http://www.jesuitasleon.es/calidad/Modelos\%20de\%20gestion\% 20de\% 20calidad.pdfMantilla, (2007)

[2] Research management: differentiations and relationships. Available at: http://revistas.usta.edu.co/index.php/hallazgos/article/viewFile/1668/1817Molero, Contreras, Casanova, (2016). Knowledge management as a tool for research productivity in the university sector. Legal Deposit: PPI200802ZU2980 / ISSN: 1856-9331. Edition No 21 Muñoz, (2000).

[3] Towards an intercultural education: Approaches and Models. Complutense University of Madrid: Education meetings. $1, \quad 81-106 . D \quad$ Dipsonible http://qspace.library.queensu.ca/bitstream/1974/628/1/sedano.pdfPezántez, (2011).

[4] Management and quality indicators of Higher Education. Master in Integrated Quality, Environment and Safety Management Systems. SaleRodríguez Polytechnic University, Castañeda, (2001).

[5] Teachers in research and innovation contexts. In Revista Iberoamericana de Educación, 25, 103-146.

[6] Recovered from the site: http://www.rieoei.org/rie25a05.htm Sánchez, (2005). Teach to investigate. A new didactics in the training of researchers in social and human sciences. Mexico. Plaza and Valdés Editores Sancho, (1990).

[7] Bibliometric indicators used in the evaluation of science and technology. Bibliographic review. Rev. Esp. Doc. Cient., K3, 3-4, 19900ñate, Urdaneta, (2016).

[8] Knowledge management for the training of researchers in university environments. Legal Deposit: PPI200802ZU2980 / ISSN: 1856-9331. Edition No 21 Ucrós, Sanchez and Cardeño, (2015).

[9] job satisfaction in teaching, research and extension, of higher education professors in Guajira Colombia. International Journal Administration \& Finance Vol. 8, No. 4, 2015, pp. 107-116. Available at: ftp://ftp.repec.org/opt/ReDIF/RePEc/ibf/riafin/riaf-v8n4-2015/RIAF-V8N4-2015-7.pdfVanderZanden, James, (1990).

[10] Manual of social psychology. Madrid: Paidos IbéricaAlonso, Tannuri, Cabrini, Pandiella, and Benavent. (2016).

[11] A bibliometric analysis in the area of Medicine: scientific collaboration between Brazil and Spain (2002-2011). Library Research: Archivonomy, Library Science and Information. Volume 30, Issue 69, May - August 2016, 
Pages205-230. Available at: https://www.sciencedirect.com/science/article/pii/S0187358X163002 Alvarado, Morales, Aguayo, (2016).

[12] Perception of educational quality: case applied to students of the Autonomous University of Nuevo León and the Instituto Tecnológico de Estudios Superiores de Monterrey. Revistadela educación superior printed version ISSN 0185-2760. Rev. educ. sup vol.45 no.180, Available at: http://www.scielo.org.mx/scielo.php?pid=S0185-27602016000400055\&script=sci_arttex, (2000).

[13] The Leadership of Educational Processes. In: A. Villa. (Coord). Leadership and Learning Organizations. III International Congress on Center Management. (1st ed., Chap. ISBN: 84-271-2338-00, pp. 299-330). Bilbao. Spain: Editorial Messenger Álvarez, Juncosa, (2014).

[14] The evaluation and accreditation of Ecuadorian higher education and editorial production. Universitas, 163181 Arbeláez, (2004).

[15] Conceptions about a quality university teaching. Spain: University of Valencia.Bricall, (2000). Quality and Accreditation. In J. M. Bricall. University 2000 (1st ed., Pp. 189-205). Madrid: Conference of Rectors of the Borbón y Fernández Spanish Universities (2017).

[16] Role of strategic educational management in the management of knowledge, science, technology and innovation in higher education. Educ. Méd. Special Article. Available at: med.https: //www.sciencedirect.com/science/article/pii/S1575181317300013 Bulgarín, (2008).

[17] Higher Education in Latin America and the Bologna Process: Scope and Challenges. UAT Science. Recovered from http://goo.gl/4yfsRyBruner, (2010).

[18] The Bologna process on the Latin American horizon: limits and possibilities. Education Magazine, special issue, 119 - 145.Buelal, Bermúdez, Sierra, Quevedo, (2008). 2008 Ranking in Research Productivity of Spanish Public Universities. Psicothema. Vol. 21, No. 2, pp. 304-312 ISSN 0214 - 9915 CODEN PSOTEG www.psicothema.com. 2009 Psicothema. Available at: http://www.redalyc.org/html/727/72711654021/Castro,Torres y Jiménez, (2016). Scientific production and perception of research by dental students. EducMed. 201 